\title{
Eutectic Ceramic Composites by Melt-Solidification
}

\author{
Takashi Goto $(\mathbb{D} * * * ; \dagger$ and Rong Tu* \\ *State Key Laboratory of Advanced Technology for Materials Synthesis and Processing, \\ Wuhan University of Technology, Wuhan 430070, China \\ **New Industry Creation Hatchery Center, Tohoku University, Sendai 980-8579, Japan
}

(Received April 6, 2019; Revised May 15, 2019; Accepted June 4, 2019)

\begin{abstract}
While high-temperature ceramic composites consisting of carbides, borides, and nitrides, the so-called ultra-high-temperature ceramics (UHTCs), have been commonly produced through solid-state sintering, melt-solidification is an alternative method for their manufacture. As many UHTCs are binary or ternary eutectic systems, they can be melted and solidified at a relatively low temperature via a eutectic reaction. The microstructure of the eutectic composites is typically rod-like or lamellar, as determined by the volume fraction of the second phase. Directional solidification can help fabricate more sophisticated UHTCs with highly aligned textures. This review describes the fabrication of UHTCs through the eutectic reaction and explains their mechanical properties. The use of melt-solidification has been limited to small specimens; however, the recently developed laser technology can melt large-sized UHTCs, suggesting their potential for practical applications. An example of laser melt-solidification of a eutectic ceramic composite is demonstrated.
\end{abstract}

Key words : Carbides, Borides, Nitrides, Composites, Microstructure

\section{Introduction}

$\mathrm{C}$ arbides, borides, and nitrides have exceptional thermomechanical and thermochemical properties and a high melting temperature, and thus, they are often called ultrahigh-temperature ceramics (UHTCs). As UHTCs are usually hard-to-sinter materials, sintering additives are needed to densify them, which inevitably degrades their high-temperature properties. Spark plasma sintering (SPS) and hotisostatic pressing can be used to fabricate UHTCs with fewer sintering additives, ${ }^{1)}$ and chemical vapor deposition (CVD) can help fabricate pure UHTCs with excellent hightemperature performance. ${ }^{2)}$ However, it is difficult to fabricate large-scale materials or materials with a complicated shape by using these techniques.

As an alternative method, melt-solidification of eutectic composites has been receiving considerable attention. ${ }^{3)}$ UHTCs are hard-to-melt materials with extremely high melting temperatures; however, the melting temperatures of UHTCs can be significantly lowered by carrying out thermodynamic reactions, typically eutectic reactions. While many carbides, borides, and nitrides (non-oxides) of UHTCs, such as $\mathrm{SiC}$ and TiN, cannot melt at normal pressure by sublimation or decomposition at high temperatures, the eutectic reaction can readily melt and solidify these ceram-

\footnotetext{
Corresponding author : Takashi Goto

E-mail : goto@imr.tohoku.ac.jp

Tel : +81-22-795-4891 Fax : +81-22-795-3175

ORCID

https://orcid.org/0000-0001-9632-0540
}

ics to produce composites.

UHTC eutectic composites have a unique self-aligned microstructure, resulting in outstanding mechanical and thermal properties. Directionally solidified eutectics (DSEs) of UHTCs have more sophisticated aligned textures, which suggests that they are promising high-temperature structural materials. Thus far, the use of UHTC eutectic composites has been limited to small-scale materials because such high temperatures were rarely achievable in the past; however, recent advanced technology using lasers or electron beams readily enables the realization of extreme high temperatures, providing practical applications for UHTCs.

Melt-solidification is a short process compared with conventional sintering, and therefore, material research using this process can be conducted efficiently. We investigated the development of UHTC composites using arc-melting, floating-zone melting, and laser melting. Arc-melting makes it easy to search for candidate materials, and floating zone melting can be used to form sophisticated directionally solidified materials. Laser melting can be used to fabricate a large-area solidified material. This paper reviews our research on UHTC eutectic composites and state-of-art laser melting techniques.

\section{The Eutectic Reaction}

The eutectic reaction is a thermodynamic feature of meltsolidification that results in two (binary) or three (ternary) solids from a multi-component liquid. Fig. 1 presents a typical phase diagram of a binary eutectic system. The melting temperature of $\mathrm{A}$ decreases with increasing content of $\mathrm{B}$ in a 


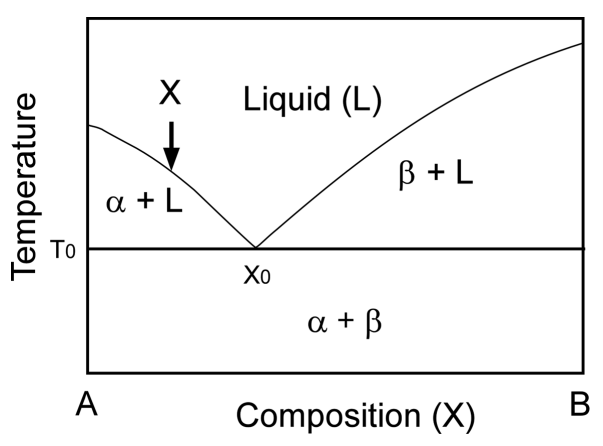

Fig. 1. Typical phase diagram of a binary eutectic system.

liquid, while that of $\mathrm{B}$ also decreases with increasing content of A. At $\mathrm{T}_{0}$, a liquid (L) and two solids, $\alpha$ and $\beta$, are in equilibrium. The lowest melting temperature is the eutectic temperature. When a liquid with a composition of $\mathrm{X}$ is cooled, the liquid solidifies into $\alpha$ and the composition of $\mathrm{X}$ in the liquid changes such that the liquid becomes B-rich close to $\mathrm{X}_{0}$. At $\mathrm{T}_{0}$ (eutectic temperature), the solidification is completed. The first solidified $\alpha$ is a primary phase, and the A-rich region is hypoeutectic. At a composition of $\mathrm{X}_{0}, \alpha$ and $\beta$ simultaneously solidify from the liquid. $\mathrm{X}_{0}$ is the eutectic composition. At the B-rich region, $\beta$ is the primary phase, and its region is hypereutectic. ${ }^{4}$ Fig. 2 demonstrates the microstructure of the $\mathrm{TiC}^{-\mathrm{TiB}_{2}}$ binary eutectic system. ${ }^{5)}$ At a
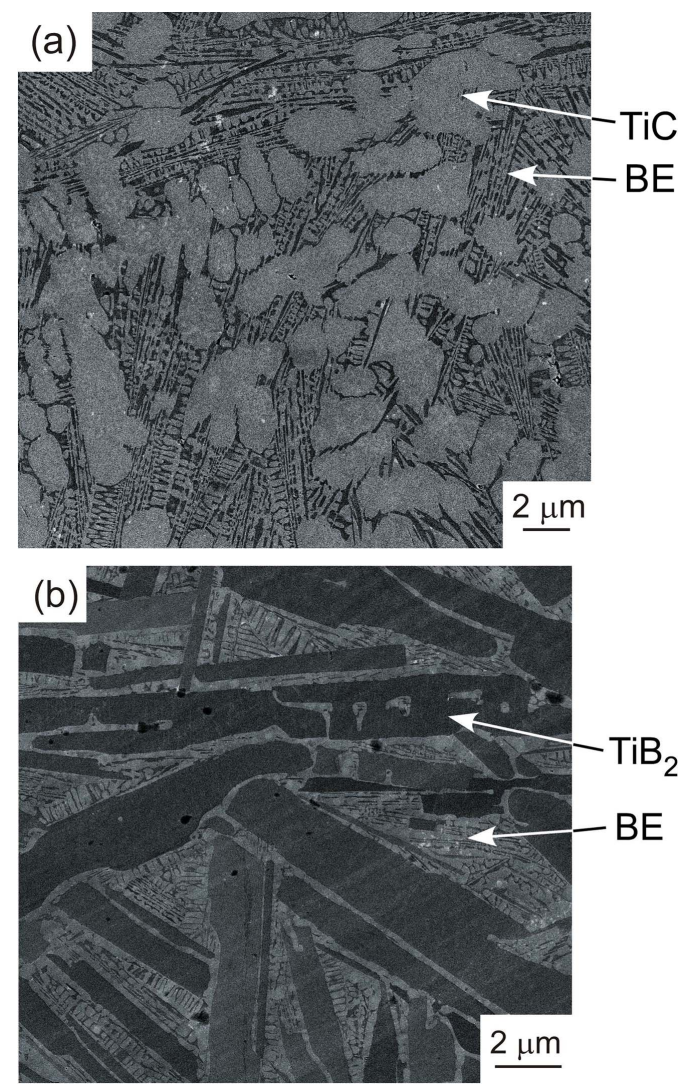

Fig. 2. Microstructure of the $\mathrm{TiC}_{-} \mathrm{TiB}_{2}$ eutectic system: hypoeutectic (a) and hypereutectic (b).

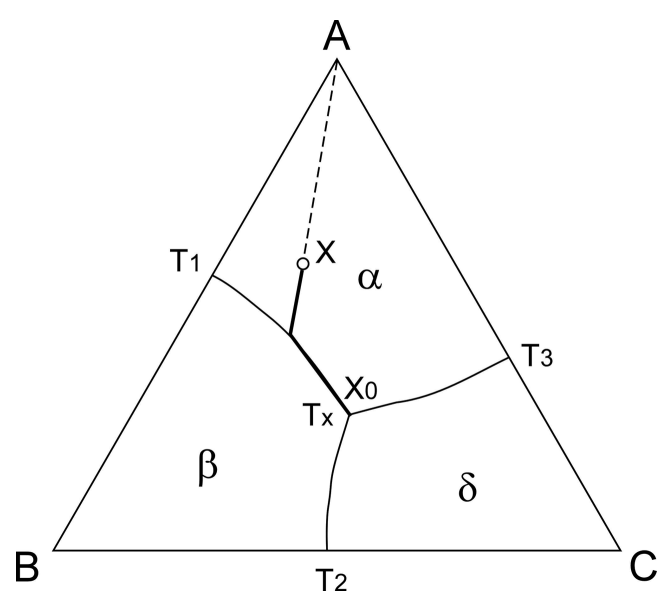

Fig. 3. Ternary eutectic phase diagram.

TiC-rich composition (hypoeutectic), TiC first solidifies as a primary phase, and finally, the $\mathrm{TiC}-\mathrm{TiB}_{2}$ binary eutectic (BE) solidifies (Fig. 2(a)). At a $\mathrm{TiB}_{2}$-rich composition (hypereutectic), $\mathrm{TiB}_{2}$ solidifies as a primary phase, and the binary eutectic (BE) finally solidifies (Fig. 2(b)). The eutectic composition with a uniform texture can be easily recognized from microstructural observations.

A ternary eutectic phase diagram is shown in Fig. 3, where the A-B, B-C, and A-C systems are eutectic with eutectic temperatures of $\mathrm{T}_{1}, \mathrm{~T}_{2}$ and $\mathrm{T}_{3}$, respectively. $\alpha, \beta$, and $\delta$ are primary phases of A-rich, B-rich and C-rich regions, respectively. $\mathrm{T}_{\mathrm{x}}$ is a ternary eutectic temperature. When a liquid with the composition of A cools, at first, the primary phase of $\alpha$ solidifies, and then the composition of the liquid changes along the $\mathrm{T}_{1}-\mathrm{T}_{\mathrm{x}}$ binary eutectic line. Finally, a ternary eutectic of the composition of $\mathrm{X}_{0}$ solidifies. Therefore, by changing the composition of the liquid, one can fabricate various kinds of composites in which a coarse primary phase is dispersed in a eutectic matrix composite or fine binary eutectics are mixed with a ternary eutectic. Fig. 4 depicts the microstructure of the $\mathrm{B}_{4} \mathrm{C}-\mathrm{TiB}_{2}-\mathrm{SiC}$ ternary

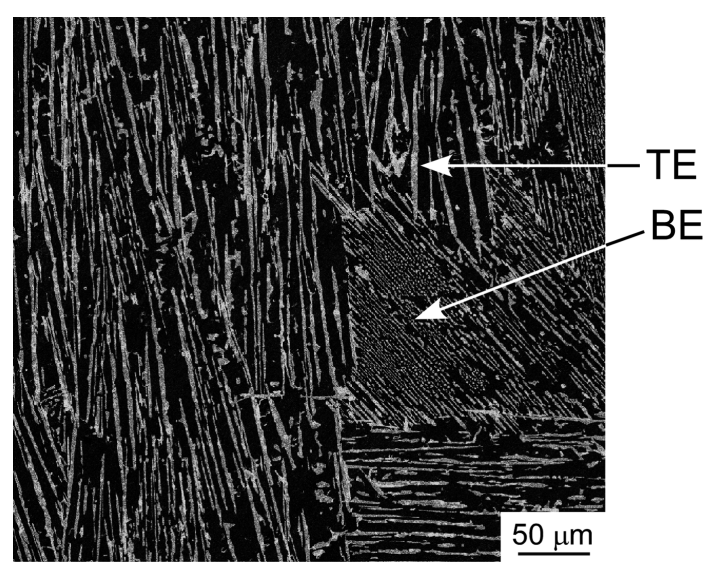

Fig. 4. Microstructure of the $\mathrm{B}_{4} \mathrm{C}-\mathrm{TiB}_{2}-\mathrm{SiC}$ ternary eutectic, a mixture of the $\mathrm{B}_{4} \mathrm{C}-\mathrm{SiC}$ binary eutectic and ternary eutectic. 
eutectic system. ${ }^{6)}$ The microstructure is a mixture of the SiC- $\mathrm{B}_{4} \mathrm{C}$ binary eutectic (BE) and the $\mathrm{B}_{4} \mathrm{C}-\mathrm{TiB}_{2}$-SiC ternary eutectic (TE). As the ternary eutectic solidifies later than the binary eutectic with a slower cooling rate, the texture of the ternary eutectic becomes coarser than that of the binary eutectic. By utilizing the eutectic reaction, not only structural ceramics but also various functional ceramics can be developed. . $^{\text {(t) }}$

The microstructure of eutectic composites is typically either rod-like (fibrous) or a lamellar texture; however, sometimes, an intermediate labyrinth (or Chinese character-like) texture can be formed. The microstructure basically changes with the composition of the material; the rodlike texture forms when the minor-phase volume fraction of a material is less than $\sim 30$ vol\%. Fig. 5(a) shows the microstructure of the $\mathrm{B}_{4} \mathrm{C}-\mathrm{TiB}_{2}$ eutectic $\left(\mathrm{B}_{4} \mathrm{C}-26\right.$ vol\% $\left.\mathrm{TiB}_{2}\right)$ : rodlike $\mathrm{TiB}_{2}$ (white) in a $\mathrm{B}_{4} \mathrm{C}$ matrix (black). $\left.{ }^{8}\right)$ Fig. 5(b) shows the microstructure of the lamellar $\mathrm{B}_{4} \mathrm{C}$-SiC eutectic $\left(\mathrm{B}_{4} \mathrm{C}-49\right.$ vol\% $\mathrm{SiC}$ ): lamellar $\mathrm{SiC}$ (white) with lamellar $\mathrm{B}_{4} \mathrm{C}$ (black). ${ }^{9}$ The microstructure of eutectics is mainly determined by minimizing the interface area of the minor phase. A rod-like texture is theoretically expected for a minor-phase volume fraction of less than $1 / \pi\left(31.8\right.$ vol\%). ${ }^{10)}$ Fig. 6 summarizes the relationship between the surface area/unit volume $\left(A_{\mathrm{v}}\right)$ and
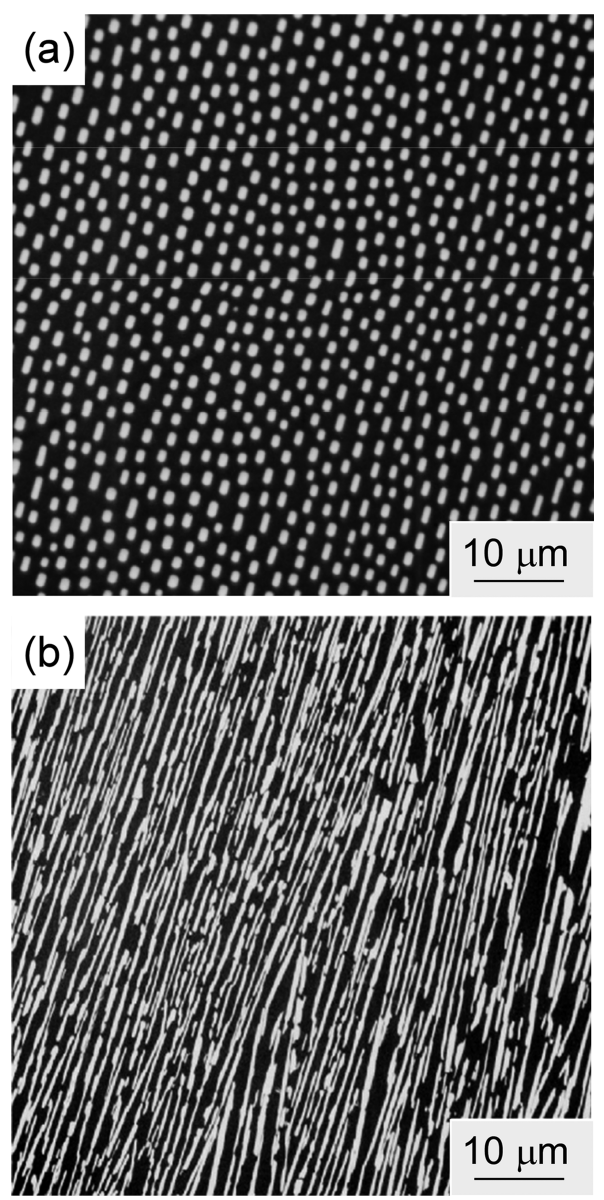

Fig. 5. Microstructure of the $\mathrm{B}_{4} \mathrm{C}-\mathrm{TiB}_{2}$ eutectic $\mathrm{B}_{4} \mathrm{C}-\mathrm{SiC}$ eutectic composites (b).

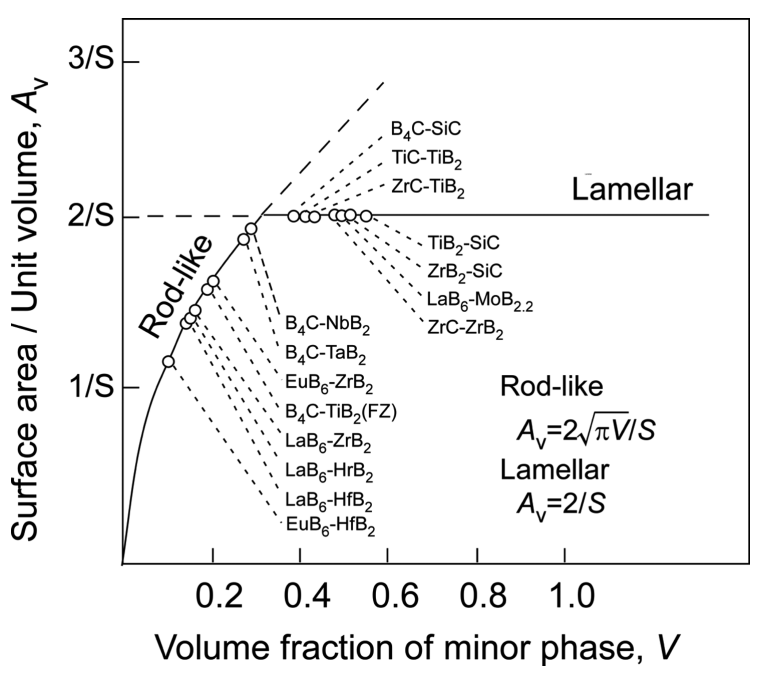

Fig. 6. Relationship between the surface area/unit volume $\left(A_{\mathrm{v}}\right)$ and volume fraction of the minor phase $(V)$ for various eutectic composites.

the volume fraction of the minor phase $(V)$ for various eutectic composites. In almost all systems, a rod-like texture is formed at a minor-phase volume fraction of less than $\sim 30$ vol\%. A lower surface energy would result in a lamellar texture at a volume fraction of less than $\sim 30 \mathrm{vol} \%$. If there is some strong interface interaction, a rod-like or labyrinth texture can be observed when the minor-phase volume fraction is more than $\sim 30$ vol\%. The $A_{\mathrm{v}}$ is given by $2 \sqrt{\pi V} / S$ and $2 / S$ for rod-like and lamellar textures, respectively, and $S$ is the spacing between rods and between lamellae in a square array. $^{10)}$

Figure 7 depicts a schematic diagram of the liquid/solid interface of the binary eutectic. At the solid-liquid interface, when the $\alpha$ phase solidifies from a liquid phase, the B component should diffuse into the neighboring $\beta$ phase. Therefore, when the cooling rate is fast, the diffusion length becomes shorter, and the texture becomes finer with an

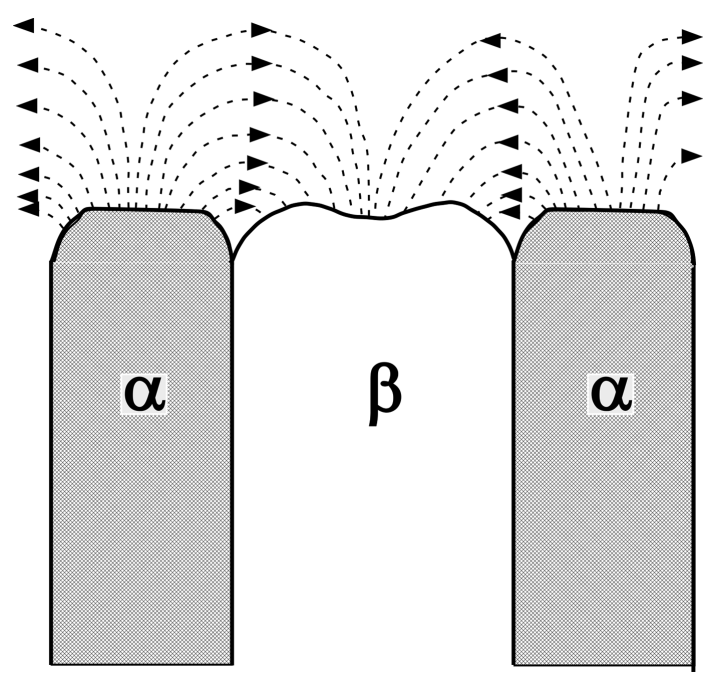

Fig. 7. Schematic diagram of the liquid/solid interface of binary eutectic composites. 


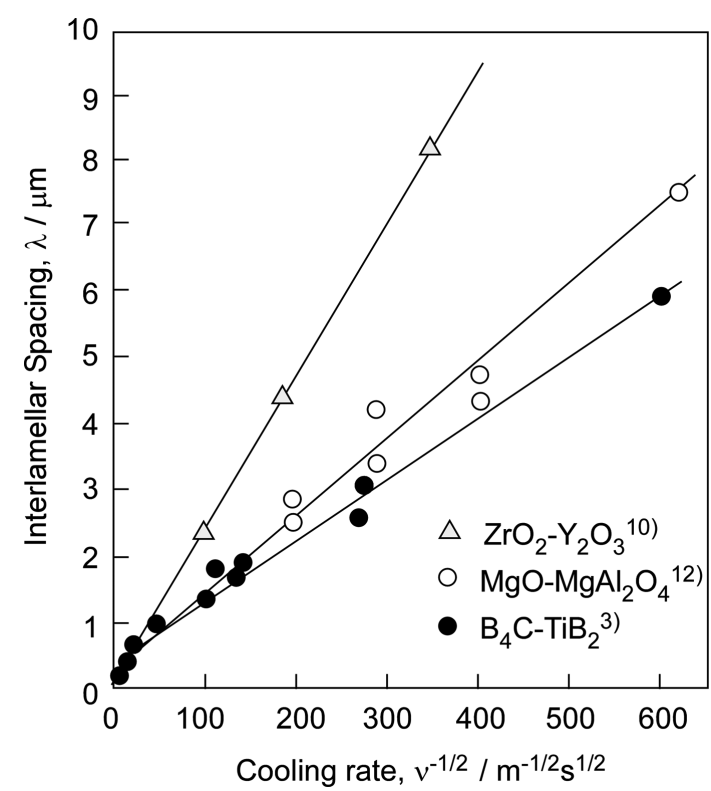

Fig. 8. Relationship between inter-lamellar (inter-rod) spacing $(\lambda)$ and cooling rate $(v)$.

increasing cooling rate. The diffusion of $\mathrm{A}$ and $\mathrm{B}$ in a liquid significantly affects the inter-lamellar (or inter-rod) spacing in the eutectic system, obeying Eq. (1): ${ }^{11)}$

$$
\lambda^{2} v=K
$$

where $v$ is the cooling (solidification) rate, and $\lambda$ is an interlamellar (or inter-rod) spacing. $K$ is a constant. Fig. 8 presents the relationship between the inter-lamellar (inter-rod) spacing and cooling rate for the $\mathrm{B}_{4} \mathrm{C}-\mathrm{TiB}_{2},{ }^{3)} \mathrm{ZrO}_{2}-\mathrm{Y}_{2} \mathrm{O}_{3}{ }^{10)}$ and $\mathrm{MgO}-\mathrm{MgAl}_{2} \mathrm{O}_{4}$ eutectic composites. ${ }^{12)}$ The $v$ vs. $\lambda^{-1 / 2}$ relationship is linear. Most eutectic systems, irrespective of whether they are metals, oxides, and non-oxides, obey Eq. (1). By using laser melting, significantly high cooling rates can be used to fabricate a material with a fine texture, while the use of a small cooling rate by floating zone melting results in a material with a coarse eutectic texture. By changing the cooling rate, the microstructure of eutectic composites can be controlled.

In general, the performance of a material depends on the size of its grains: the smaller the grain size is, the higher the hardness and strength are; this is known as the Hall-Petch relationship. ${ }^{13,14)}$ The grain sizes of ceramics produced by sintering are usually not smaller than that of the source powder. However, in eutectic composites, the grain size (inter-lamellar spacing) decreases with the square root of the cooling rate. The inter-lamellar spacing decreases in the order of floating zone melting, arc melting, and laser melting, and a finer texture and stronger ceramic can be developed by using a process with a higher cooling rate.

\section{Binary and Ternary UHTC Eutectic Composites}

$\mathrm{Al}_{2} \mathrm{O}_{3}-\mathrm{GaAlO}_{3}$ oxide eutectic composite ceramics have been studied as structural ceramics owing to their high strength and high ductility at high temperatures. ${ }^{15)}$ The DSE of $\mathrm{Al}_{2} \mathrm{O}_{3}-\mathrm{GaAlO}_{3}$ is also promising as a functional ceramic for scintillating. ${ }^{16)}$ While oxide eutectic composite ceramics have been intensively investigated, studies on UHTC eutectic composites is rather scarce. Most studied UHTCs are SiC-based composites. As SiC has high strength, high thermal shock, and oxidation resistance at high temperatures, it has been widely used as a structural ceramic. ${ }^{17)}$ In order to improve the properties of $\mathrm{SiC}$, many $\mathrm{SiC}$-based composites have been developed by solid-state sintering. As $\mathrm{SiC}$ sublimates, it does not melt at a normal pressure at high temperatures. However, SiC can melt by adding a second phase, such as $\mathrm{B}_{4} \mathrm{C}$, by the eutectic reaction. The earliest studied UHTC eutectic composite was the $\mathrm{SiC}_{4} \mathrm{~B}_{4} \mathrm{C}$ system. ${ }^{18)}$ The $\mathrm{SiC}-\mathrm{B}_{4} \mathrm{C}$ eutectic composite was also reported to have high thermoelectric performance. ${ }^{19)}$ The DSE of SiC- $\mathrm{B}_{4} \mathrm{C}$ showed excellent mechanical and thermochemical properties. ${ }^{9}$ ) Although $\mathrm{SiC}$ would severely degrade by active oxidation at a low oxygen partial pressure and high temperatures, such as in a space, ${ }^{20)}$ studies have been widely conducted to improve the oxidation resistance of $\mathrm{SiC}_{-} \mathrm{ZrB}_{2}{ }^{21)}$ SiC- $\mathrm{ZrB}_{2}$ oxidizes to $\mathrm{SiO}_{2}$ and $\mathrm{B}_{2} \mathrm{O}_{3}$, whereby $\mathrm{B}_{2} \mathrm{O}_{3}$ would suppress the active oxidation and could heal the cracks on the surface of $\mathrm{SiO}_{2}$. The $\mathrm{SiC}-\mathrm{ZrB}_{2}$ system is binary eutectic. The SiC- $\mathrm{ZrB}_{2}$ eutectic composite has higher oxidation resistance than the $\mathrm{SiC}_{-} \mathrm{ZrB}_{2}$ sintered composite. ${ }^{22)}$ Fig. 9 depicts the microstructure of the $\mathrm{SiC}-\mathrm{ZrB}_{2}$ eutectic composite. The eutectic composition is $\mathrm{SiC}-51 \mathrm{vol} \% \mathrm{ZrB}_{2} \cdot{ }^{22)}$ Although the second phase $\left(\mathrm{ZrB}_{2}\right)$ is more than 30 vol\% where the lamellar texture would be expected, the microstructure is a labyrinth texture, a partially connected rod-like texture. Hexagonal $\mathrm{ZrB}_{2}$ has a strong interface connection with the cubic $\mathrm{SiC}$ matrix, resulting in the labyrinth texture.

Figure 10 depicts the $\mathrm{SiC}_{-} \mathrm{TiB}_{2}$-TiC ternary phase diagram. Each end member is a binary eutectic, and therefore, the $\mathrm{SiC}_{-} \mathrm{TiB}_{2}$-TiC system is ternary eutectic. ${ }^{23)} \mathrm{TiB}_{2}$ has an $\mathrm{AlB}_{2}$ structure like that of $\mathrm{ZrB}_{2}$. SiC-TiB ${ }_{2}$ is a eutectic whose

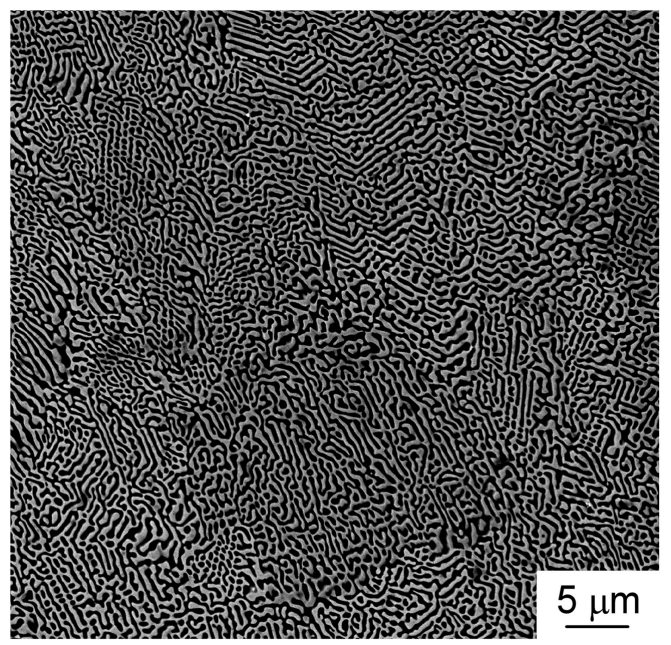

Fig. 9. Microstructure of the $\mathrm{SiC}-\mathrm{ZrB}_{2}$ eutectic composite. 


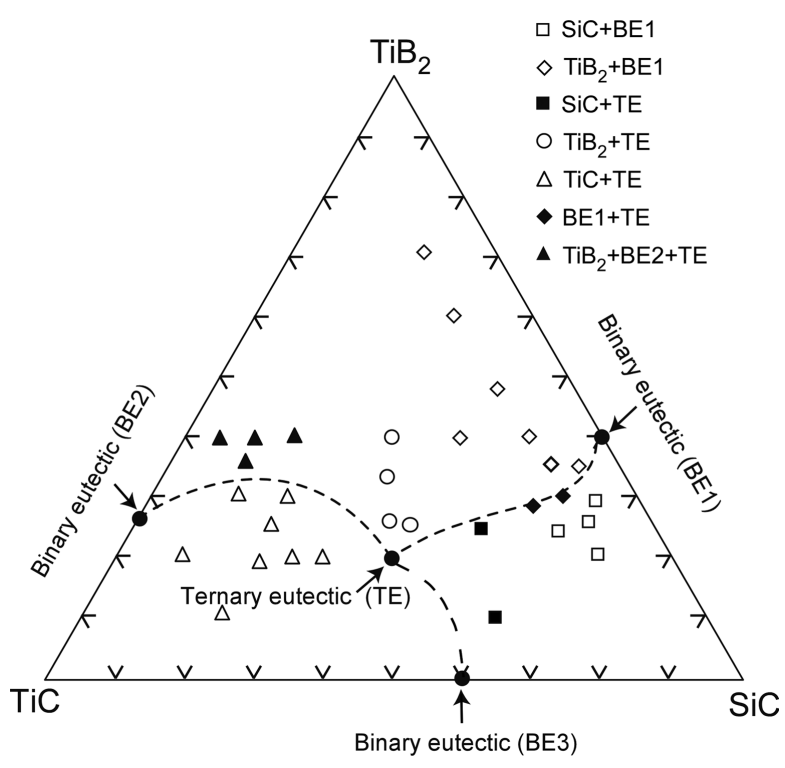

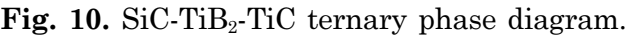

eutectic composition is $\mathrm{SiC}-45$ vol\% $\mathrm{TiB}_{2}{ }^{24)} \mathrm{TiB}_{2}$ has high electrical and thermal conductivities, and thus, the $\mathrm{SiC}_{-} \mathrm{TiB}_{2}$ eutectic composite has high strength and high thermal stability with high electrical and thermal conductivities. The hardness of the $\mathrm{SiC}_{-} \mathrm{TiB}_{2}$ eutectic composite is the highest owing to its fine microstructure. ${ }^{24)}$ The $\mathrm{SiC}^{2}-\mathrm{TiB}_{2}$ eutectic composite also has a labyrinth texture. The $\mathrm{SiC}-\mathrm{TiC}$ system is eutectic, and its eutectic composition is $\mathrm{SiC}-60$ vol\% $\%$ TiC. $\mathrm{SiC}$ and $\mathrm{TiC}$ have a cubic structure, with no specific relationship between the two phases; the SiC-TiC eutectic composite has a common lamellar texture. The SiC-TiC composite has been widely studied. Sintered SiC-TiC composite exhibits high densification and strength when its composition is close to the eutectic composition. ${ }^{25)} \mathrm{SiC}-\mathrm{TiC}$ composites have been also fabricated through $\mathrm{CVD}^{26)}$ and sputtering. ${ }^{27)}$ The vapor-deposited SiC-TiC composites have a fine microstructure, and the $\mathrm{SiC}-\mathrm{TiC}$ composite formed using CVD has a high fracture toughness, which is similar to that observed for the SiC-TiC composite with the eutectic composition. Vapor-phase deposited materials with a eutectic composition can also have significantly fine microstructures. The $\mathrm{TiC}^{-\mathrm{TiB}_{2}}$ system is a binary eutectic whose eutectic composition is $\mathrm{TiC}-32$ vol\% $\mathrm{TiB}_{2} \cdot{ }^{5}$ ) As the volume fraction of the second phase $\left(\mathrm{TiB}_{2}\right)$ is close to $30 \mathrm{vol} \%$, the microstructure of the $\mathrm{TiC}^{-\mathrm{TiB}_{2}}$ eutectic composites is a mixture of rod-like and lamellar texture. $\mathrm{TiC}$ has a wide-ranging stoichiometry from $\mathrm{TiC}_{0.5}$ to $\mathrm{TiC}_{1.0}$, and the eutectic temperature decreases with decreasing carbon content in TiC. Both TiC and TiN have a rock-salt structure and exhibit similar properties. The $\mathrm{TiB}_{2}$ - TiN system is also eutectic. The TiC-TiN system is a completely solid-solution, and therefore, the $\mathrm{TiB}_{2}$-TiCN system is eutectic, and its eutectic composition is $\mathrm{TiB}_{2}-69$ vol $\% \mathrm{TiC}_{\mathrm{x}} \mathrm{N}_{1-\mathrm{x}}$ at $\mathrm{x}=0.67$. $^{28)}$ Fig. 11 shows the surface microstructure of the $\mathrm{TiB}_{2}-\mathrm{TiC}_{\mathrm{x}} \mathrm{N}_{1-\mathrm{x}}$ eutectic composite. A huge numbers of rod-like $\mathrm{TiC}_{\mathrm{x}} \mathrm{N}_{1-\mathrm{x}}$
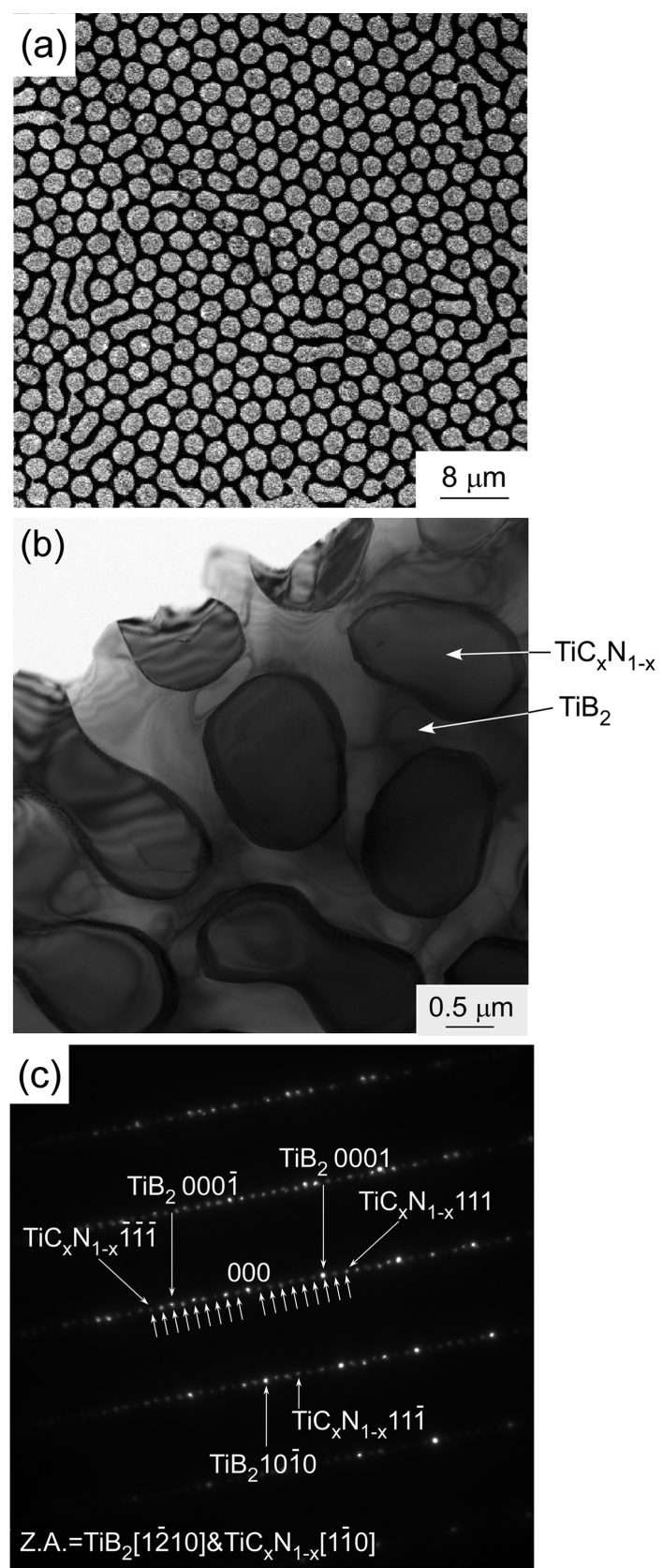

Fig. 11. Surface microstructure of the $\mathrm{TiB}_{2}-\mathrm{TiC}_{\mathrm{x}} \mathrm{N}_{1 \cdot \mathrm{x}}$ eutectic composite (a). (b) is a higher magnification of (a). (c) is a diffraction pattern of the interface between $\mathrm{TiB}_{2}$ (white) and $\mathrm{TiC}_{\mathrm{x}} \mathrm{N}_{1-\mathrm{x}}$ (gray).

phases can be seen in the $\mathrm{TiB}_{2}$ matrix (Fig. 11(a)). Some $\mathrm{TiC}_{\mathrm{x}} \mathrm{N}_{1-\mathrm{x}}$ rods have a hexagonal shape, and two or three $\mathrm{TiC}_{\mathrm{x}} \mathrm{N}_{1-\mathrm{x}}$ rods are partially connected. It is unusual for the $\mathrm{TiC}_{\mathrm{x}} \mathrm{N}_{1-\mathrm{x}}$ phase still to be rod-like, even at $\sim 70 \mathrm{vol} \%$ of $\mathrm{TiC}_{\mathrm{x}} \mathrm{N}_{1-\mathrm{x}} . \quad<0001>\mathrm{TiB}_{2}$ is parallel to $<111>\mathrm{TiC}_{\mathrm{x}} \mathrm{N}_{1-\mathrm{x}}$, and $(11 \overline{2} 0) \mathrm{TiB}_{2}$ is parallel to $(\overline{2} 02) \mathrm{TiC}_{\mathrm{x}} \mathrm{N}_{1-\mathrm{x}}$. Both $\mathrm{TiB}_{2}$ and $\mathrm{TiC}_{\mathrm{x}} \mathrm{N}_{1-\mathrm{x}}$ have a single crystalline structure. $\mathrm{TiC}_{\mathrm{x}} \mathrm{N}_{1-\mathrm{x}}$ can be coherently connected to $\mathrm{TiB}_{2}$. A strong interaction at the $\mathrm{TiC}_{\mathrm{x}} \mathrm{N}_{1-\mathrm{x}} / \mathrm{TiB}_{2}$ interface may result in a rod-like texture at a high $\mathrm{TiC}_{\mathrm{x}} \mathrm{N}_{1-\mathrm{x}}$ volume content of $\sim 70 \mathrm{vol} \%$. A dark contrast 
can be seen at the interface between $\mathrm{TiB}_{2}$ (white) and $\mathrm{TiC}_{\mathrm{x}} \mathrm{N}_{1-\mathrm{x}}$ (gray) (Fig. 11(b)). The diffraction of the gray contrast area implies a long-ranged structure, where nine spots of (111) $\mathrm{TiC}_{\mathrm{x}} \mathrm{N}_{1-\mathrm{x}}$ can be seen between $(1 \overline{2} 10) \mathrm{TiB}_{2}$ at $\mathrm{x}=0.67$ (Fig. 11(c)). Nine layers of $d_{111}(2.25 \mathrm{~nm})$ agree with seven layers of $\mathrm{d}_{1 \overline{2} 10}(2.24 \sim 2.25 \mathrm{~nm})$. Even in the simple system of $\mathrm{TiB}_{2}-\mathrm{TiC}_{\mathrm{x}} \mathrm{N}_{1-\mathrm{x}}$, a new compound or a new structure can be found. ${ }^{29)}$ Research on the use of UHTCs at temperatures higher than their melting temperature is scarce. More new compounds or new structures may be found by using meltsolidification. As $\mathrm{Zr}$ has similar chemical properties to $\mathrm{Ti}$, like $\mathrm{Ti}$ compounds, the $\mathrm{ZrB}_{2}-\mathrm{ZrC}{ }^{30)} \mathrm{ZrB}_{2}-\mathrm{ZrN}{ }^{31)}$ and $\mathrm{ZrB}_{2}-\mathrm{ZrCN}^{32)}$ systems are also binary eutectic, where the eutectic composition of the second phase $(\mathrm{ZrC}, \mathrm{ZrN}$, and $\mathrm{ZrCN}$ ) is $\sim 60 \mathrm{vol} \%$ with a rod-like texture. The ternary eutectic composition of $\mathrm{SiC}_{-} \mathrm{TiB}_{2}-\mathrm{TiC}$ is $42 \mathrm{SiC}-26 \mathrm{TiB}_{2}-32 \mathrm{TiC}$ (vol\%). The $\mathrm{B}_{4} \mathrm{C}-\mathrm{TiB}_{2}-\mathrm{SiC}$ system is also ternary eutectic, and the eutectic composition is $64 \mathrm{~B}_{4} \mathrm{C}-7 \mathrm{TiB}_{2}-29 \mathrm{SiC}$ (vol\%). ${ }^{6}$ Fig. 12 depicts the microstructure of directionally solidified ternary $\mathrm{SiC}_{-} \mathrm{TiB}_{2}-\mathrm{TiC}$ and $\mathrm{B}_{4} \mathrm{C}-\mathrm{TiB}_{2}-\mathrm{SiC}$ eutectic composites. Both ternary eutectic composites have a lamellar texture. The SiC (black) and TiC (white) phases are parallel, but the $\mathrm{TiB}_{2}$ (gray) phase is slanted toward the $\mathrm{SiC}$ and $\mathrm{TiC}$ phases in the $\mathrm{SiC}_{-} \mathrm{TiB}_{2}-\mathrm{TiC}$ eutectic composite (Fig. 12(a)). The $\mathrm{B}_{4} \mathrm{C}$, $\mathrm{TiB}_{2}$, and $\mathrm{SiC}$ phases are in parallel with a lamellar texture. The $\mathrm{TiB}_{2}$ phase disperses finely at the $\mathrm{B}_{4} \mathrm{C} / \mathrm{SiC}$ interface (Fig. 12(b)).

Hf has similar chemical properties as $\mathrm{Zr}$ and Ti. Therefore, the phase diagram of Hf-based compounds is also similar to those of Zr- and Ti-based compounds. Fig. 13 shows the ternary phase diagram of the $\mathrm{B}_{4} \mathrm{C}-\mathrm{HfB}_{2}-\mathrm{SiC}$ system. ${ }^{33)}$
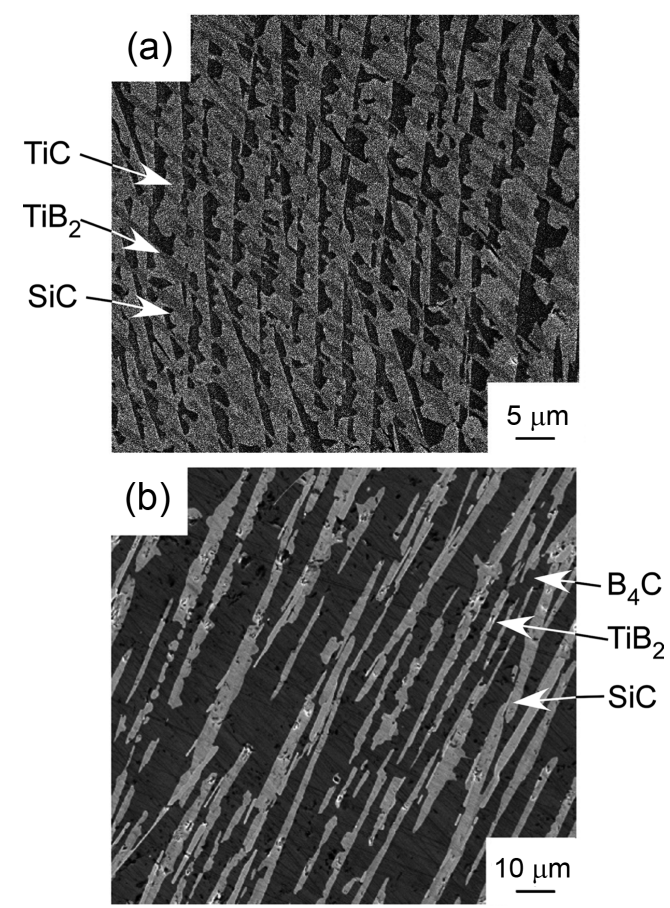

Fig. 12. Microstructure of the ternary $\mathrm{SiC}_{-} \mathrm{TiB}_{2}-\mathrm{TiC}(\mathrm{a})$ and $\mathrm{B}_{4} \mathrm{C}-\mathrm{TiB}_{2}-\mathrm{SiC}$ eutectic composites (b).
As the melting temperature of $\mathrm{Hf}\left(2222^{\circ} \mathrm{C}\right)$ is higher than those of $\mathrm{Ti}\left(1812^{\circ} \mathrm{C}\right)$ and $\mathrm{Zr}\left(1852^{\circ} \mathrm{C}\right)$, Hf-based compounds have higher melting temperatures then Ti- and Zr-based compounds. Many Hf-based compounds are promising UHTCs. The $\mathrm{B}_{4} \mathrm{C}-\mathrm{SiC},{ }^{7} \mathrm{~B}_{4} \mathrm{C}-\mathrm{HfB}_{2}{ }^{33)}$ and $\mathrm{SiC}-\mathrm{HfB}_{2}$ systems are binary eutectic, and the ternary eutectic composition is $49 \mathrm{~B}_{4} \mathrm{C}-14 \mathrm{HfB}_{2}-37 \mathrm{SiC}$ (vol\%). Fig. 14 depicts the microstructure of the $\mathrm{B}_{4} \mathrm{C}-\mathrm{HfB}_{2}$-SiC ternary eutectic composite by arc melting, where $\mathrm{B}_{4} \mathrm{C}$ is black, $\mathrm{SiC}$ is gray, and $\mathrm{HfB}_{2}$ is the white phase. The three phases are finely dispersed. As the binary and ternary compounds containing $\mathrm{SiC}, \mathrm{B}_{4} \mathrm{C}$, and $\mathrm{HfB}_{2}$ are promising UHTCs, the mechanical properties (hardness and fracture toughness, $K_{\mathrm{IC}}$ ) of these composites have been investigated. Fig. 15 presents the Vickers hardness and fracture toughness $\left(K_{\mathrm{IC}}\right)$ of binary and ternary $\mathrm{B}_{4} \mathrm{C}-\mathrm{HfB}_{2}$-SiC composites. ${ }^{34-42}$ Generally, high hardness materials have a low fracture toughness. The hardness has a trade-off relationship with fracture toughness. Although many researchers have tried to develop high hardness with high fracture toughness ceramics by using conventional solid-state sintering, great effort is needed to produce good materials by sintering. Instead, melt solidification methods

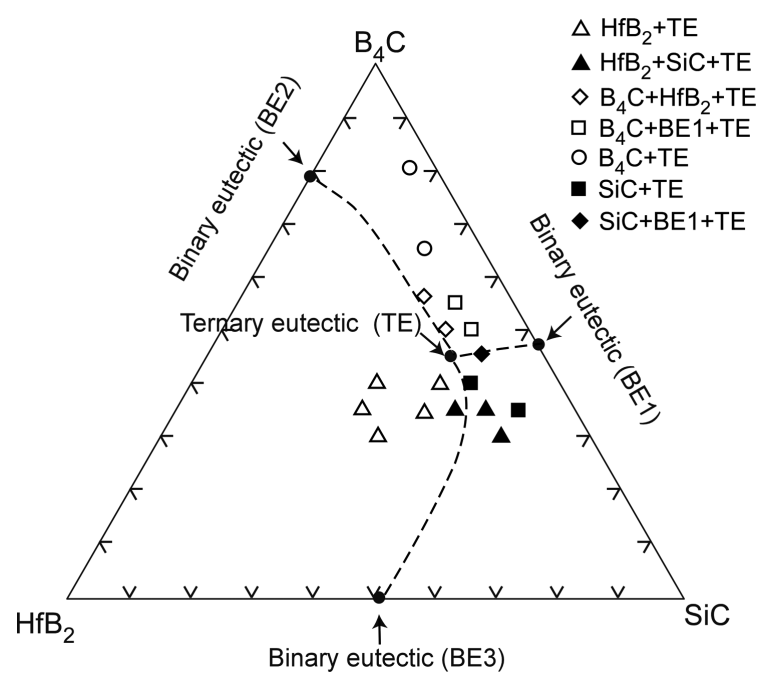

Fig. 13. Ternary phase diagram of the $\mathrm{B}_{4} \mathrm{C}-\mathrm{HfB}_{2}-\mathrm{SiC}$ system.

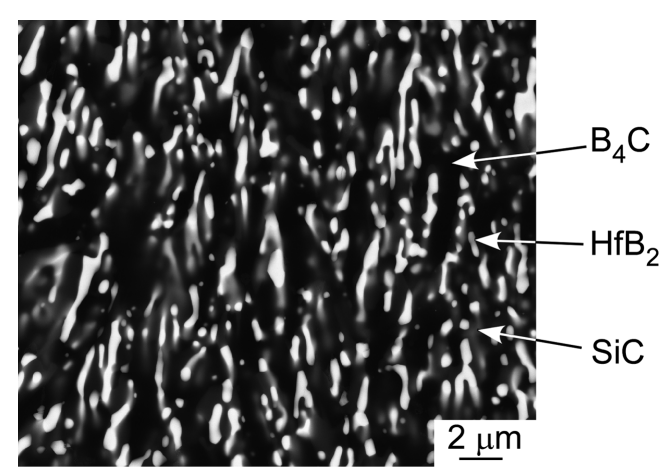

Fig. 14. Microstructure of the $\mathrm{B}_{4} \mathrm{C}-\mathrm{HfB}_{2}-\mathrm{SiC}$ ternary eutectic composite where $\mathrm{B}_{4} \mathrm{C}$ is black, $\mathrm{SiC}$ is gray, and $\mathrm{HfB}_{2}$ is white. 


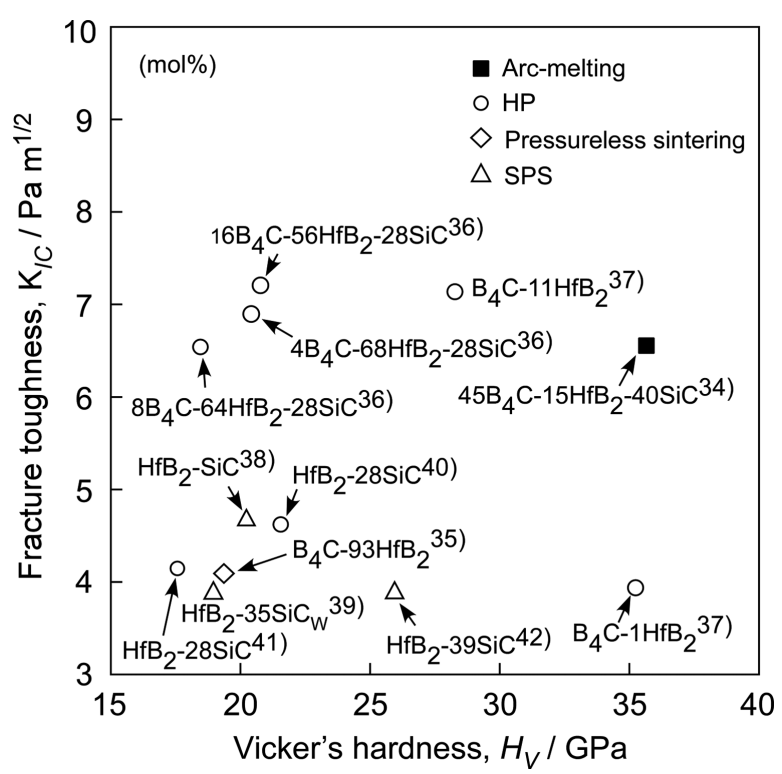

Fig. 15. Vickers hardness $\left(H_{V}\right)$ and fracture toughness $\left(K_{\mathrm{IC}}\right)$ of binary and ternary $\mathrm{B}_{4} \mathrm{C}-\mathrm{HfB}_{2}-\mathrm{SiC}$ composites.

such as arc-melting are easy, and a short time is needed to research high performance ceramic materials. The $\mathrm{B}_{4} \mathrm{C}-\mathrm{HfB}_{2}$-SiC eutectic composites show higher hardness and toughness than those fabricated by hot-press (HP) and SPS. Fig. 16 depicts the Vickers indentation and crack formation of the $\mathrm{B}_{4} \mathrm{C}-\mathrm{HfB}_{2}-\mathrm{SiC}$ eutectic composite. As the microstructure is small, the cracks are deflected and branched, causing high fracture toughness.
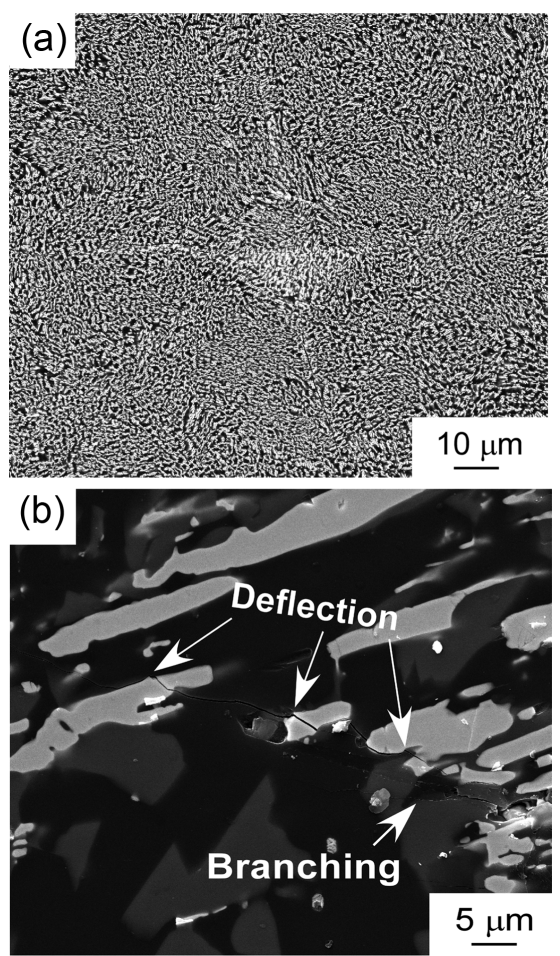

Fig. 16. Vickers indentation (a) and crack formation (b) of the $\mathrm{B}_{4} \mathrm{C}-\mathrm{HfB}_{2}-\mathrm{SiC}$ eutectic composite.

\section{DSE Composite by Laser Melting}

Although floating zone melting has often been used to fabricate DSEs, the size of UHTCs is usually limited to several tens of millimeters. On the other hand, a high temperature technology using a laser or electron beam is currently under development, and a high temperature of more than $3000^{\circ} \mathrm{C}$ can be readily produced. In particular, laser technology does not require high vacuum, so it is appropriate to melt UHTCs, particularly those containing volatile compounds such as $\mathrm{SiC}$ and TiN. Laser technology has been widely used to melt metals for cladding and welding; however, it has rarely been used to melt ceramics. While the direction of solidification in floating zone melting is axial to the materials, it is inclined to be in the scan direction of the laser. There is basically no limitation on the size of materials in laser melting as long as the laser can scan them. Larrea et al. melted and solidified the $\mathrm{ZrO}_{2}-\mathrm{Al}_{2} \mathrm{O}_{3}$ eutectic composite by using a $\mathrm{CO}_{2}$ laser $\left(1 \mathrm{~kW} / \mathrm{cm}^{2}\right) .{ }^{43)}$ The laser was modified to have a length and width of 20 and $0.5 \mathrm{~mm}$, respectively, by using a parabolic mirror, and the $\mathrm{ZrO}_{2}-\mathrm{Al}_{2} \mathrm{O}_{3}$ eutectic composite was directionally melted and solidified using a scanning laser. Chen et al. used the Nd:YAG laser $(2 \mathrm{~kW})$ with a length and width of 12.7 and $5 \mathrm{~mm}$, respectively, and the WC- $\mathrm{W}_{2} \mathrm{C}$ eutectoid-like composite was fabricated. ${ }^{44}$

Arc-melting is a type of pseudo-directional solidification, in which melted materials are solidified directionally from a water-cooled copper hearth. Arc-melting allows for the easy melting of numerous metals, and it is a useful method for searching for high-performance materials in a short time. On the other hand, laser melting has no size limitation, and its solidification rate is high and directional when a scanning laser is used. Once a good material is found by arcmelting, laser melting can be applied for practical applications to fabricate wide-area UHTC eutectic composites. SiC is a promising UHTC, and $\mathrm{CrB}_{2}$ has high corrosion/oxidation resistance with a relatively low melting temperature $\left(2100^{\circ} \mathrm{C}\right){ }^{45)}$ This is advantageous for the fabrication of widearea ceramic materials by laser melting. We first melted and solidified $\mathrm{SiC}-\mathrm{CrB}_{2}$ composites by arc-melting to determine their eutectic composition; then, laser melting was applied to obtain the $\mathrm{SiC}-\mathrm{CrB}_{2}$ eutectic composite. The $\mathrm{SiC}-\mathrm{CrB}_{2}$ system is a binary eutectic whose eutectic composition is $\mathrm{SiC}-81$ vol\% $\mathrm{CrB}_{2}$, and it has a rod-like texture. As shown in Fig. 8, the microstructure of the eutectic composite becomes finer as the cooling rate increases. In the case of laser melting, the cooling rate increases with an increasing scanning rate.

Figure 17 presents the effect of the laser scanning rate on the cross-sectional microstructure of the $\mathrm{SiC}-\mathrm{CrB}_{2}$ eutectic composite. The composite has a course texture and a melted depth of about $20 \mu \mathrm{m}$ at a scanning rate of $0.3 \mathrm{~mm} / \mathrm{s}$ (Fig. 17(a)). SiC grains (black) are coarsened, and the depth of the melted area is thin. A melted pool forms on the surface when the scanning rate is slow. The laser is reflected on the liquid pool surface. Immediately below the melted zone, the 

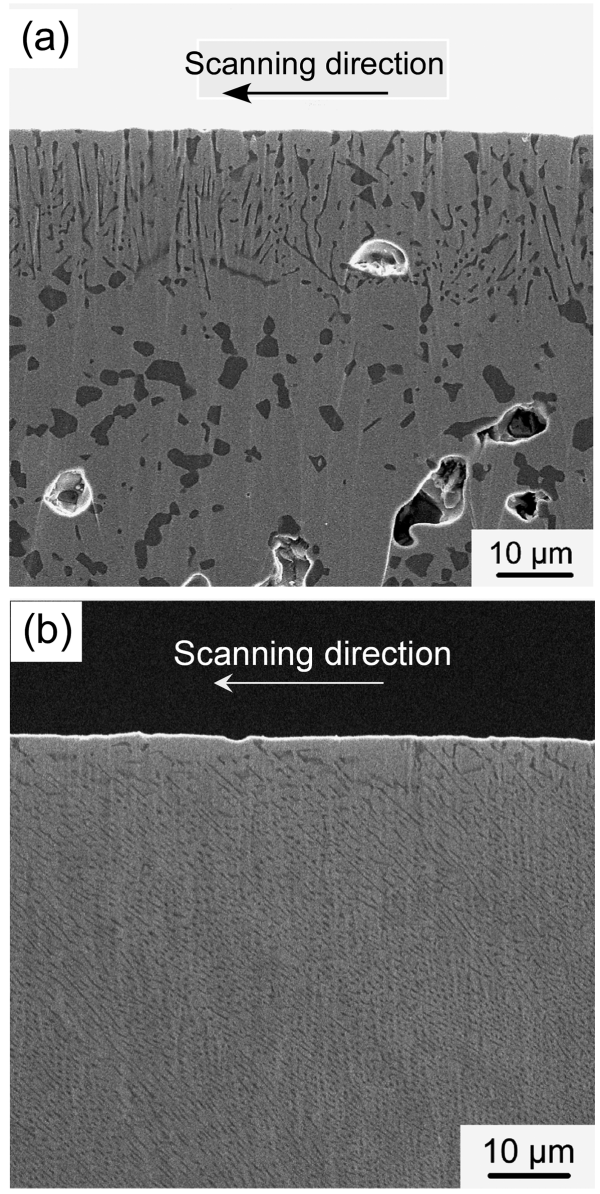

Fig. 17. Effect of the laser scanning rate on the cross-sectional microstructure of the $\mathrm{SiC}-\mathrm{CrB}_{2}$ eutectic composite: $0.3 \mathrm{~mm} / \mathrm{s}$ (a) and $1.8 \mathrm{~mm} / \mathrm{s} \mathrm{(b)}$.

$\mathrm{SiC}-\mathrm{CrB}_{2}$ composite is solid-state sintered. The laser can also be used for sintering. At the laser scanning rate of 1.8 $\mathrm{mm} / \mathrm{s}$, the melted depth is about $300 \mu \mathrm{m}$ with no melted pool; furthermore, the composite has a slightly slanted directionally oriented rod-like texture (Fig. 17(b)). $\mathrm{CrB}_{2}$ has a hexagonal $\mathrm{AlB}_{2}$ structure, and the growth direction is $<0001>$. As the laser scan has a transverse direction, the $<0001>$ oriented $\mathrm{CrB}_{2}$ is slightly slanted toward the scanning direction of the laser.

\section{Summary}

Ceramics have generally been fabricated by solid-state sintering because they have a high melting temperature; therefore, the melt-solidification process (casting) has rarely been applied to ceramics, particularly UHTCs. However, by using the eutectic reaction, UHTCs can be melted and solidified. The eutectic reaction enables the fabrication of ceramics with a self-aligned microstructure by controlling the composition and cooling rate. Research on UHTCs above their melting temperatures has rarely been conducted. The phase diagrams of UHTCs in terms of the melting temperature are also not well known. Further study is, therefore, needed. With the advancement of high-temperature technology, such as lasers, the DSE of UHTCs can be readily produced and used for high-temperature applications.

\section{REFERENCES}

1. Z. A. Munir, D. V. Quach, and M. Ohyanagi, "Electric Current Activation of Sintering: A Review of the Pulsed Electric Current Sintering Process," J. Am. Ceram. Soc., 94 [1] 1-19 (2011).

2. Z. Hu, D. Zheng, R. Tu, M. Yang, Q. Li, M. Han, S. Zhang, L. Zhang, and T. Goto, "Structural Controlling of HighlyOriented Polycrystal 3C-SiC Bulks via Halide CVD," Materials, 12 [3] 390-40 (2019).

3. W.-T. Chen, R. M. White, T. Goto, and E. C. Dickey, "Directionally Solidified Boride and Carbide Eutectic Ceramics," J. Am. Ceram. Soc., 99 [6] 1837-51 (2016).

4. A. R. West, Solid State Chemistry and its Applications; $2^{\text {nd }}$ Eds, pp. 325-57, Wiley, 2014.

5. W. Li, R. Tu, and T. Goto, "Preparation of Directionally Solidified $\mathrm{TiB}_{2}$-TiC Eutectic Composites by a Floating Zone Method," Mater. Lett., 60 [6] 839-43 (2006).

6. W. Li, R. Tu, and T. Goto, "Preparation of Directionally Solidified $\mathrm{B}_{4} \mathrm{C}-\mathrm{TiB}_{2}$-SiC Ternary Eutectic Composites by a Floating Zone Method and Their Properties," Mater. Trans., 46 [9] 2067-72 (2005).

7. K. Nishimoto, Y. Yokota, S. Kurosawa, Y. Fujimoto, N. Kawaguchi, K. Fukuda, and A. Yoshikawa, "Crystal Growth of $\mathrm{LiF} / \mathrm{LiYF}_{4}$ Eutectic Crystals and Their Luminescent Properties,” J. Eur. Ceram. Soc., 34 [9] 2117-21 (2014).

8. I. Gunjishima, T. Akashi, and T. Goto, "Characterization of Directionally Solidified $\mathrm{B}_{4} \mathrm{C}-\mathrm{TiB}_{2}$ Composites Prepared by a Floating Zone Method," Mater. Trans., 43 [4] 712-20 (2002).

9. I. Gunjishima, T. Akashi, and T. Goto, "Characterization of Directionally Solidified $\mathrm{B}_{4} \mathrm{C}-\mathrm{SiC}$ Composites Prepared by a Floating Zone Method," Mater. Trans., 43 [9] 230915 (2002).

10. R. L. Ashbrook, "Directionally Solidified Ceramic Eutectics," J. Am. Ceram. Soc., 60 [9-10] 428-35 (1977)

11. J. D. Hunt, "Development in Eutectics," J. Cryst. Growth, 3-4 82-91 (1968).

12. F. L. Kennard, R. C. Bradt, and V. S. Stubican; "Eutectic Solidification of $\mathrm{MgO}-\mathrm{MgAl}_{2} \mathrm{O}_{4}$," J. Am. Ceram. Soc., 56 [11] 566-69 (1973).

13. E. O. Hall, "The Deformation and Aging of Mild Steel," Proc. Phys. Soc., London, Sect. B, 64 [9] 747-53 (1951).

14. N. J. Petch, "The Cleavage Strength of Polycrystals," J. Iron Steel Inst., 174 25-8 (1953).

15. Y. Waku, N. Nakagawa, T. Wakamoto, H. Ohtsubo, K. Shimizu, and Y. Kohtoku, "A Ductile Ceramic Eutectic Composite with High Strength at 1,873 K," Nature, 389 [4] 49-52 (1997).

16. Y. Ohashi, N. Yasui, T. Suzuki, M. Watanabe, T. Den, K. Kamada, Y. Yokota, and A. Yoshikawa, "Orientation Relationships of Unidirectionally Aligned $\mathrm{GdAlO}_{3} / \mathrm{Al}_{2} \mathrm{O}_{3}$ Eutectic Fibers," J. Eur. Ceram. Soc., 34 [15] 3849-57 (2014).

17. N. S. Jacobson, "Corrosion of Silicon-Based Ceramics in 
Combustion Environments," J. Am. Ceram. Soc., 76 [1] 328 (1993).

18. J. Hong, K. E. Spear, and V. S. Stubican, "Directional Solidification of $\mathrm{SiC}_{-} \mathrm{B}_{4} \mathrm{C}$ Eutectic: Growth and Some Properties," Mater. Res. Bull., 14 [6] 775-83 (1979).

19. T. Goto, E. Ito, M. Mukaida, and T. Hirai, "Microstructure and Seebeck Coefficient of SiC-B 4 C Eutectic Ceramics," $J$. Jpn. Soc. Powder Powder Metall., 41 [11] 1304-7 (1994).

20. T. Narushima, T. Goto, Y. Iguchi, and T. Hirai, "High Temperature Active Oxidation of Chemically VaporDeposited Silicon Carbide in an $\mathrm{Ar}-\mathrm{O}_{2}$ Atmosphere," J. Am. Ceram. Soc., 74 [10] 2583-86 (1991).

21. I. Akin, M. Hotta, F. C. Sahin, O. Yucel, G. Gollor, and T. Goto, "Microstructure and Densification of $\mathrm{ZrB}_{2}-\mathrm{SiC}$ Composites Prepared by Spark Plasma Sintering," J. Eur. Ceram. Soc., 29 [11] 2379-85 (2009).

22. R. Tu, H. Hirayama, and T. Goto, "Preparation of $\mathrm{ZrB}_{2}$ SiC Composites by Arc Melting and Their Properties," $J$. Ceram. Soc. Jpn., 116 [3] 431-35 (2008).

23. W.-J. Li, R. Tu, and T. Goto, "Preparation of TiC-TiB ${ }_{2}-\mathrm{SiC}$ Ternary Eutectic Composites by Arc-Melting and Their Characterizations," Mater. Trans., 47 [4] 1193-97 (2006).

24. W.-J. Li, R. Tu, and T. Goto, "Preparation of $\mathrm{TiB}_{2}-\mathrm{SiC}$ Eutectic Composite by an Arc-Melted Method and its Characterization," Mater. Trans., 46 [11] 2504-8 (2005).

25. H. Endo, M. Ueki, and H. Kubo, "Hot Pressing of SiC-TiC Composite," J. Mater. Sci., 25 2503-6 (1990).

26. T. Goto and T. Hirai, "Microstructures of SiC-TiC in-situ Composites Prepared by Chemical Vapor Deposition," $J$. Jpn. Soc. Powder Powder Metall., 34 [9] 487-90 (1987).

27. G. Osugi, A. Ito, M. Hotta, and T. Goto, "Microstructure and Hardness of SiC-TiC Nanocomposite Thin Films Prepared by Radiofrequency Magnetron Sputtering," Thin Solid Films, 520 [18] 5851-55 (2012).

28. E. J. Cheng, H. Katsui, R. Tu, and T. Goto, "Rod-like Eutectic Structure of Arc-Melted $\mathrm{TiB}_{2}-\mathrm{TiC}_{\mathrm{x}} \mathrm{N}_{1-\mathrm{x}}$ Composite," J. Eur. Ceram. Soc., 34 [9] 2089-94 (2014).

29. E. J. Cheng, H. Katsui, R. Tu, and T. Goto, "Long-Range Ordered Structure of Ti-B-C-N in a $\mathrm{TiB}_{2}-\mathrm{TiC}_{\mathrm{x}} \mathrm{N}_{1-\mathrm{x}}$ Eutectic Composite," J. Am. Ceram. Soc., 97 [8] 2423-26 (2014).

30. E. J. Cheng, Y. Li, J. Sakamoto, S. Han, H. Sun, J. Noble, H. Katsui, and T. Goto, "Mechanical Properties of Individual Phases of $\mathrm{ZrB}_{2}-\mathrm{ZrC}$ Eutectic Composite Measured by Nanoindentation," J. Eur. Ceram. Soc., 37 [13] 4223-27 (2017).

31. E. J. Cheng, H. Katsui, and T. Goto, "Microstructure of $\mathrm{ZrB}_{2}$-ZrN Directionally Solidified Eutectic Composite by Arc-Melting," J. Asian Ceram. Soc., 6 [1] 102-7 (2018).

32. E. J. Cheng, H. Katsui, and T. Goto, " $\mathrm{ZrB}_{2}-\mathrm{ZrC}_{\mathrm{x}} \mathrm{N}_{1-\mathrm{x}}$ Eutectic Composites Produced by Melt Solidification," J. Am. Ceram. Soc., 99 [2] 667-73 (2016).

33. R. Tu, N. Li, Q. Li, S. Zhang, L. Zhang, and T. Goto, "Effect of Microstructure on Mechanical, Electrical and
Thermal Properties of $\mathrm{B}_{4} \mathrm{C}-\mathrm{HfB}_{2}$ Composites Prepared by Arc Melting,” J. Eur. Ceram. Soc., 36 [16] 3929-37 (2016).

34. R. Tu, N. Li, Q. Li, S. Zhang, L. Zhang, and T. Goto, "Microstructure and Mechanical Properties of $\mathrm{B}_{4} \mathrm{C}-\mathrm{HfB}_{2}-\mathrm{SiC}$ Ternary Eutectic Composites Prepared by Arc Melting," J. Eur. Ceram. Soc., 36 [3] 959-66 (2016).

35. J. Zou, G.-J. Zhang, and Y.-M. Kan, "Pressureless Densification and Mechanical Properties of Hafnium Diboride Doped with $\mathrm{B}_{4} \mathrm{C}$ : from Solid State Sintering to Liquid Phase Sintering," J. Eur. Ceram. Soc., 30 [12] 2699-705 (2010).

36. L. Weng, X. Zhang, J. Han, W. Han, and C. Hong, "The Effect of $\mathrm{B}_{4} \mathrm{C}$ on the Microstructure and ThermoMechanical Properties of $\mathrm{HfB}_{2}$-based Ceramics," J. Alloys Compd., 473 [1-2] 314-18 (2009).

37. K. Sairam, J. K. Sonber, T. S. R. C. Murthy, C. Subramanian, R. C. Hubli, and A. K. Suri, "Development of $\mathrm{B}_{4} \mathrm{C}-\mathrm{HfB}_{2}$ Composites by Reaction Hot Pressing," Int. J. Refract. Met. Hard Mater., 35 32-40 (2012).

38. H. Wang, S.-H. Lee, and L. Feng, "HfB ${ }_{2}-\mathrm{SiC}$ Composite Prepared by Reactive Spark Plasma Sintering," Ceram. Int., 40 [7] 11009-13 (2014).

39. C. Musa, R. Orrù, D. Sciti, L. Silvestroni, and G. Cao, "Synthesis, Consolidation and Characterization of Monolithic and $\mathrm{SiC}$ Whiskers Reinforced $\mathrm{HfB}_{2}$ Ceramics," J. Eur. Ceram. Soc., 33 [3] 603-14 (2013).

40. X. Zhang, L. Weng, J. Han, S. Meng, and W. Han,” Preparation and Thermal Ablation Behavior of $\mathrm{HfB}_{2}$-SiC-based Ultra-High-Temperature Ceramics under Severe Heat Conditions," Int. J. Appl. Ceram. Technol., 6 [2] 134-44 (2009).

41. M. Gasch, D. Ellerby, E. Irby, S. Beckman, M. Gusman, and S. Johnson, "Processing, Properties and Arc Jet Oxidation of Hafnium Diboride/Silicon Carbide Ultra High Temperature Ceramics," J. Mater. Sci., 39 [19] 5925-37 (2004).

42. F. Monteverde, C. Melandri, and S. Guicciardi, "Microstructure and Mechanical Properties of an $\mathrm{HfB}_{2}+30$ vol.\% SiC Composite Consolidated by Spark Plasma Sintering," Mater. Chem. Phys., 100 [2-3] 513-19 (2006).

43. A. Larrea, G. F. de la Fuente, R. I. Merino, and V. M. Orera, " $\mathrm{ZrO}_{2}-\mathrm{Al}_{2} \mathrm{O}_{3}$ Eutectic Plates Produced by Laser Zone Melting," J. Eur. Ceram. Soc., 22 [2] 191-98 (2002).

44. W.-T. Chen, C. H. Meredith, and E. C. Dickey, "Growth and Microstructure-Dependent Hardness of Directionally Solidified WC- $-\mathrm{W}_{2} \mathrm{C}$ Eutectoid Ceramics," J. Am. Ceram. Soc., 98 [7] 2191-96 (2015).

45. S. S. Ordan'yan, D. D. Nesmelov, D. P. Danilovich, and Y. P. Udalov, "Revisiting the Structure of $\mathrm{SiC}-\mathrm{B}_{4} \mathrm{C}-\mathrm{Me}^{\mathrm{d}} \mathrm{B}_{2}$ Systems and Prospects for the Development of Composite Ceramic Materials based on Them," Russ. J. Non. Ferr. Met., 58 [5] 545-51 (2017). 